\title{
FROM IDENTITY TO ORGANISATION IDENTITY: THE EVOLUTION OF A CONCEPT
}

\author{
CL VAN TONDER \\ BC LESSING \\ Department of Human Resources Management \\ RAU University
}

\begin{abstract}
The view that corporate and/or organisation identity is a contributing factor to organisational success, is increasingly observed in the media. At the same time research interest in the concept appears to be on the increase. While identity is not a novel concept and has presented in different forms, it remains shrouded in ambiguity and is in need of more precise articulation. The present study revisited the origins of the identity concept and reviewed various perspectives on identity. A specific meaning structure and theoretical framework for the organisation identity concept is proposed and it is concluded that contemporary views of identity are increasingly embracing earlier psychological perspectives.
\end{abstract}

\section{OPSOMMING}

Die siening dat korporatiewe en/of organisasie-identiteit 'n bydraende faktor tot organisasiesukses is, word toenemend in die media waargeneem. Navorsingsbelangstelling in die konsep skyn terselfdertyd toe te neem. Terwyl identiteit geensins 'n nuwe konsep is nie en in verskillende vorme voorkom, bly dit in vaagheid gehul en word 'n meer duidelike omskrywing daarvan benodig. Die huidige studie het die oorsprong van die indentiteitskonsep nagespeur en verskeie perspektiewe op identiteit in oënskou geneem. 'n Bepaalde betekenisstruktuur en teoretiese raamwerk word vir die identiteitskonsep voorgestel en die gevolgtrekking word gemaak dat kontemporêre sienings van identiteit toenemend besig is om vroeëre psigologiese perspektiewe te omsluit.

Organisations have become a taken for granted phenomenon in contemporary society. Indeed they have steadily grown and assumed centre stage in societal evolution and development, with many latter day global corporations financially more powerful than smaller nation states. Startling results produced by a Royal Dutch/Shell study of enduring organisations (De Geus, 1997) have however revealed that the life expectancy of organisations is rapidly declining (currently between 40 and 50 years). Indeed, organisational decline and bankruptcy were increasing at disturbing rates (Korten, 1995; Labich, 1994) with wave upon wave of costly mergers, acquisitions, corporate restructurings, and related organisational change events adversely impacting on the workforce, their dependants and ultimately society at large (Offerman \& Gowing, 1990).

Various approaches and many attempts at accounting for the premature demise of organisations have proposed that environmental forces and economic and managerial reasons are to blame. The popularity of these arguments have however waned over time, with many a scholar now arguing that they are over-simplistic, focus on symptoms and do not acknowledge the more fundamental psychological nature of organisational decline (cf. Levinson, 1994).

Recent commentary in the business and scientific press have suggested that an inadequate or neglected "identity" may be at the root of the expensive path to corporate failure (Labich, 1994), and indeed the high failure rate of mergers and acquisitions (Balmer \& Dinnie, 1999). This proposed relationship between identity and organisational performance is however not a novel idea, with some business leaders in the USA acknowledging this linkage as early as the 1980s (Wathen, 1986). At the time it was indicated in some quarters (Chajet, 1989) that US executives are increasingly viewing corporate identity as a mainstream business activity. More recently Balmer and Gray (2000) accounted for this greater "identity" awareness among senior business managers by arguing that environmental trends such as accelerating product life cycles, deregulation, privatisation, an increasingly competitive environment, and several others, were forcing managers to view identity with greater importance. In the South

Requests for copies should be addressed to: $C$ van Tonder, Department of Human Resource Management, RAU University, PO Box 524, Auckland Park, 2006
African business context, for example, the results of an opinion poll among chief executive officers listed growth, identity and entering new markets as the top strategic priority for the period 1999 to 2003, followed by global competitiveness and productivity (Robertson, 1999). An equally plausible reason for the salience of the identity issue in managerial quarters has been suggested by Christensen and Askegaard (2001) when they stated that marketing scholars and practitioners have worked consistently at keeping identity on the managerial agenda. Regardless of the reasons advanced however, an implicit relationship between identity and organisational functioning and performance is generally assumed.

The conclusions of, among other, the Royal Dutch/Shell study of enduring organisations (De Geus, 1997), which emphasised a strong sense of identity as one of four key survival factors for organisations, further bolster the view that identity is an important element in organisational performance. These views are significant in the sense that identity (or corporate or organisation identity) as a concept is beginning to surface in nonadvertising and non-marketing arenas as a possible "theory" which could account for business failure (or success), and suggests that "identity" as research subject, with the objective to inform business practice, should receive more attention from the scientific community.

However, as the ensuing discussion will reveal, the root concept of identity is difficult to define and consequently derivative concepts such as corporate and/or organisation identity are prone to similar ailments. A more integrated and precise articulation of the organisation identity concept and hence of identity and related concepts, are both necessary and urgent. This study briefly considers the origins of the identity and organisation identity concepts and juxtaposes different perspectives on identity in order to establish more precise meaning parameters for the organisation identity concept. An encapsulating theoretical framework is used as context for articulating the role and purpose of organisation identity in organisational functioning.

The problematic of identity

The term identity is derived from the Latin word "idem" meaning "the same" (Abend, 1974), with its first known use dating back to approximately $1570 \mathrm{AD}$ when it was used as an 
expression to convey the quality or condition of being the same, being absolutely or essentially similar and referring to a sense of unity (Van Tonder, 1987). Erik Erikson who is generally credited with popularising the concept as a consequence of his work in the field of individual psychology (Westin, 1983) described it as an inner sense of sameness and a continuity of character (Erikson, 1959). The term is however more frequently described in terms of the uniqueness, solidarity, autonomy, continuity over time, and the discreteness of the person (referred to as objective identity), which is differentiated from the person's sense of (having an) identity or subjective identity (Van Tonder, 1987).

While identity is not a novel concept and, indeed, has presented in different forms and contexts - notably as "corporate identity" in the business environment - it remains a concept shrouded in ambiguity. Evidence of the problematic nature of identity abounds. Erikson (1959, p. 102) for example stressed that "...the term itself retains some ambiguity", while Albert and Whetten (1985, p. 265) argued that identity is a profound and consequential issue, but so difficult an issue that it is best avoided. Following an in-depth exploration of the identity concept Van Tonder (1987) for example concluded that the concept was illdefined and that the inconsistent interpretation and articulation of identity was largely due to the abstract, unspecified, and ambiguous nature of the phenomenon. The interpretation and consequently the utility value of the concept was further compromised by a variety of established semantic practices and an abundance of personality concepts that do not clearly differentiate identity from the self, the self-concept and self-image (Bourne, 1978; Van Tonder, 1987). This in turn casts doubt on the concept's usefulness in theory development and empirical research, which underscored the need for a more precise articulation of the identity concept, and prompted the reformulation and definition of the concept by Van Tonder (1987).

Turning to the notion of identity within an organisational context, it is not entirely unexpected to find Albert and Whetten (1985) commenting on the inherent ambiguity and abstract nature of the organisation identity concept, and the absence of an adequate theoretical framework to guide research and practice. This ambiguity is further exacerbated by the practice of using the concept interchangeably with concepts such as corporate identity and corporate image. The interchangeable and imprecise use of key concepts and terminology is in fact a common criticism of the field (Stewart, 1991; Van Heerden, 1993; Van Heerden \& Puth, 1995). Moreover, very little scholarly research has been conducted on the subject, with academics not devoting adequate attention to the subject of corporate identity (Stewart, 1991). Most of the available literature is considered anecdotal in nature and has been written by consultants who wish to promote agencies and/or services rather than test or challenge hypotheses (Melewar, Saunders, \& Balmer, 2001).

The upsurge in interest in the corporate identity phenomenon has been echoed by contemporary research on the organisation identity phenomenon, which culminated in a special issue of The Academy of Management Review with six papers devoted to the subject (Albert, Ashforth \& Dutton, 2000). This upsurge of interest in the perceived utility value of the concepts identity and identification is attributed, in part, to the rediscovery of the importance of "meaning" in organisational functioning (Albert et al., 2000), and the insight into the character and behaviour of organisations and their members, that are generated by the concepts (Gioia, Shultz \& Corley, 2000). Contemporary research on the subject matter, however, still wrestle with essentially the same limitations and problems observed more than a decade ago and scholars are still debating the meaning parameters of a complex, abstract and vague organisation identity concept (cf. Albert et al., 2000; Hogg \& Terry, 2000; Scott \& Lane, 2000; Van Tonder, 1987; 1999). Apart from the latter, and the abundant public relations and advertising perspectives, scant attention has been given, generally, to the notion of identity within an organisational context.
Given this context, several research questions were formulated for the present study:

- Even though the concept of corporate identity has been popularised by the public relations and advertising disciplines, what essentially is organisation identity? Indeed, does it exist and can it be differentiated from corporate identity and corporate image?

- What would the role (purpose and function) of organisation identity be, and can it be linked - theoretically - to organisational functioning, as Labich (1994) would have the reader believe?

Research that provides answers to these questions (and indeed the many more that could be phrased) should bring clarity to the prevailing confusion around the use of the various identity concepts and possibly provide alternative arguments to account for the less than desirable levels of organisational performance (and the premature demise of organisations).

The purpose of the study was consequently stated as to investigate and determine the meaning parameters and theoretical relevance of the organisation identity concept. More specific research objectives derived from the latter, focused on exploring and defining organisation identity from a theoretical perspective - in relation to similar concepts in use such as corporate identity, and to a lesser extent corporate image - and articulating the role and contribution of organisation identity in terms of organisational functioning.

\section{Identity or personal identity}

The identity concept as applied in a psychological sense, predates the emergence of the organisation identity concept substantially. The prevailing consciousness of organisation identity will consequently (and unavoidably) be immersed in the meaning context created by the psychological use of the identity concept and the common understanding arising from the concept's usage in colloquial language. For this reason it is argued (Van Tonder, 1999) that a study of organisation identity cannot commence without considering the "root" concept of identity, or personal identity as it has also been known.

As a result of the conceptual dilemmas observed with the identity concept at the time, which hindered progress in terms of theory development and consequently empirical testing of theory, Van Tonder (1987) commenced with a systematic process of conceptual purification that entailed an in-depth analysis of the concept from several perspectives:

- A historical semantic analysis of terminology such as soul, spirit, psyche, self, ego, personality, character, individual, and identity. The observed similarities and differences in the meanings ascribed to these terms in colloquial language usage, as well as changes observed over a period well in excess of 470 years, served as basis for conceptually separating identity from terminology such as personality, psyche, self, and so forth.

- An analysis of the personality theory and structures of several notable scholars (personologists) with the objective of isolating and demarcating a more exact psychological meaning for the identity concept.

- An analysis of recent (at the time) theoretical perspectives on the self, the self-concept and identity.

- Given the preceding analyses, a final reconceptualisation of the identity concept and its role and function within personality theory, using systems and differentiation theories as primary vehicles.

While a review of the mentioned analyses is beyond the scope of the current discussion, the key conclusions of the author are noteworthy for several reasons. Firstly they offered a consolidation of literature focused on the identity or personal identity of the individual (as well as small group identity), and as such established a platform for launching empirical research, and secondly, provided a baseline for evaluating subsequent 
contributions and/or pursuing related avenues of theoretical interest. In essence this study concluded that identity:

- is a psychological construct which forms part of the personality of the individual and is instrumental in the identification and demarcation of the individual within and against his/her environment;

- has the primary role of integrating the various structures and sub-structures of the individual so that the person could act as a unified entity on his/her environment, and in so doing ensure focused, timely adaptation, and ultimately survival;

- in the process of performing this integration role, emphasises the uniqueness, inner solidarity and continuity of the individual over time - which typically surface in attributes, skills, attitudes and other features of the individual (refer also Table 1 which contrasts key features of early definitions of identity and group identity);

- is established through a process of identity formation, drawing on interactions with the environment, and introspection and analysis by the individual;

- evolves through successive stages of the individual life cycle in concert with the evolutionary development of other features of the organism; and

- may be adversely impacted on, and lead to identity crises if the challenges encountered during the successive stages in the life cycle are not adequately mastered.

It is also observed that identity crises will prompt tentative search behaviour with the purpose of establishing or reestablishing the distinctiveness of the individual (which has been compromised and became diffused or was lost as a result of an experienced identity crisis). The process of identity acquisition is a continuous and dynamic process during which the identity of the individual is constantly reaffirmed and further developed.

By way of summary it is observed that Van Tonder (1987, p. 52) argued that identity consists of an objective and subjective element. Objective identity is defined as a dynamic cognitive gestalt, which describes the individual, and conveys the uniqueness, solidarity, autonomy, discreteness and continuity of the individual over time. Subjective identity on the other hand refers to the individual's sense of identity (the person's awareness of his/her identity). Group identity similarly consists of an objective and subjective element, where the former refers to the cognitive gestalt of that unvarying and permanent combination of characteristics of the group, which is consistently and continuously recognised as differentiating the group from others as being an irreplaceable unit - one of a kind (Van Tonder, 1987)

The preceding perspective on the nature of the psychological concept of identity serve as theoretical grounding for clarifying and defining the concept of organisation identity. However, as the literature will attest, a variety of related concepts such as organisation image and corporate identity contribute to a lack of clarity and subsequent confusion. With the objective of clearly delineating and articulating the concept of organisation identity, both organisation or corporate image and corporate identity will be reviewed briefly.

\section{Corporate identity and corporate image}

The prolific writing on the topic of corporate identity over the last decade or so is indicative of a growing awareness of the subject both in scholarly and business quarters (Christensen \& Askegaard, 2001; Balmer \& Stotvig, 1997; Kiriakidou \& Millward, 2000) and among behavioural science professionals (Gorb, 1992) and attests to the increasing theoretical and practical interest in the ideational dimensions of organisations (Alvesson, 1990). A substantial base of quasi-theoretical literature at a superficial level currently characterises the domain of corporate identity and corporate image. Despite the fact that academics from the marketing and management domains have recently started contributing to the literature base, the bulk of the available literature is still leaning predominantly towards the practitioner perspective (Alessandri, 2001).

While a great many viewpoints have been expressed and a vast array of definitions on these concepts has been published (Van Heerden \& Puth, 1995), this has, interestingly enough, not contributed to greater precision in the usage of the identity and image concepts and a general lack of consistency is still in evidence (Christensen \& Askegaard, 2001). In the absence however of an adequate theory base and a lack of systematic research (Stewart, 1991) i.e. "...not a mature academic area" (Alessandri, 2001, p. 173), the conceptual boundaries of the concepts have become diffused and contributed to confusion and the continued practice of using the concepts interchangeably. While it is generally acknowledged that corporate image and corporate identity are associated (Ind, 1990; Stewart, 1991; Van Heerden \& Puth, 1995) this relationship in itself appears to be a source of confusion. It is for example not uncommon to encounter views expressing either similarities between corporate identity and corporate image (Zinkhan, 1990), or indicating that the two concepts are closely bound

TABLe 1

\section{KEY FEATURES: DEFINITIONS OF IDENTITY AND GROUP IDENTITY} (ADAPTED FROM VAN TONDER, 1987)

\begin{tabular}{|c|c|c|}
\hline Identity as intra-psychic quality & Identity as product of social interaction & Group identity \\
\hline $\begin{array}{l}\text { Identity is defined as: } \\
\text { - Personal uniqueness } \\
\text { - Continuity of the person over time } \\
\text { The above elements are widely supported by a } \\
\text { large number of researchers. } \\
\text { Other aspects also identified as denoting identity, } \\
\text { but perhaps less frequently cited include: } \\
\text { - The autonomy, integrity and goal directedness } \\
\text { of the individual } \\
\text { - The discreteness or unity of the individual over } \\
\text { time and place } \\
\text { - A differentiation process between the self and } \\
\text { the environment }\end{array}$ & $\begin{array}{l}\text { From this orientation, identity is: } \\
\text { - Described as a matrix of interpersonal relations } \\
\text { - Defined in relation to a structured social world. } \\
\text { cited elements of identity, the concept has been } \\
\text { defined as a complex balance of individual and } \\
\text { general elements, including cultural inputs and } \\
\text { group memberships, and as an enduring and } \\
\text { dynamic process. } \\
\text { In addition, several descriptions of identity } \\
\text { emphasise the following or elements thereof: } \\
\text { - Individual characteristics including biographical, } \\
\text { - historical and several other features, } \\
\text { - Thes, social position and social relations, } \\
\text { The role and contribution of time (past, present, } \\
\text { future) and } \\
\text { - The dynamic nature of identity. } \\
\text { An important distinction is drawn between } \\
\text { objective identity (the fact of identity) and } \\
\text { subjective identity (the sense of identity). }\end{array}$ & $\begin{array}{l}\text { Group identity is frequently defined as } \\
\text { - The inner solidarity or psychological unity } \\
\text { of the group, a sense of "we/us“ } \\
\text { The boundaries of the group are emphasised } \\
\text { as point of departure for defining identity } \\
\text { - The uniqueness of the group } \\
\text { Clear differentiation from other groups, } \\
\text { displaying a special character over time and } \\
\text { remaining in control of own activities } \\
\text { - The group's specific social position within } \\
\text { a network of inter-group relations, against a } \\
\text { broader socio-historical context and time frame - } \\
\text { conveying a strong environmental focus, often } \\
\text { characterised by so-called reference groups which } \\
\text { serve as place markers for the relevant group. }\end{array}$ \\
\hline
\end{tabular}


together (Stewart, 1991). The conceptual proximity of the two concepts appears to have contributed to a reciprocal "spill over" of meaning from one concept into the domain of the other - to the extent that both concepts have adopted features of the other.

A source of complexity compounding the existing difficulties experienced with the terminology is the existence of various approaches to, and distinct schools of thought within the corporate identity literature (Balmer, 1995). The most established and prominent of these streams hails from the corporate communications and public relations field, and emphasises the visual and design components of the organisation as the essence of corporate identity. This perspective is represented by those that view corporate identity as the visual manifestation and projection of a desired identity, notably through means such as the company's name (Kohli \& Hemnes, 1995) and its logo, corporate colours, tagline, slogans, and symbols (for example Halloran, 1985; O’Malley, 1992; Schmitt, 1995; Schmitt \& Pan, 1994; Wathen, 1986; Zinkhan, 1993). Several authors also include the physical design and physical facilities of the organisation (Capowski, 1993; Grossman, 1994; O'Malley, 1992). The emphasis placed on the visual components of the organisation as a means to influence or manipulate (control and manage) the perceptions, which the public and other stakeholders develop in respect of the organisation, is a salient feature of this approach.

Less prominent, but gaining ground is the school of thought that relates corporate identity to the company's mission, philosophy, and culture - essentially arguing that corporate identity depicts the innate and distinct personality or character of the organisation (for example Ackerman, 1984; Balmer, 1995; Kiriakidou \& Millward, 2000). Proponents of this view argue that the typical visual attributes of the organisation are (or should be) the manifestations of the underlying distinctive character of the organisation, and imply alignment or congruency between organisation character and appearance. This approach appears to be more closely aligned with the traditional, psychological concept of identity. Indeed, there is a growing recognition that corporate identity can be related to the fundamental and psychological concept of identity (Ackerman, 1984; Gorb, 1992). In this context, corporate identity is idealised as the distinctive qualities or personality of the organisation, which reside within and drive the organisation. The professional and business literature are flushed with references to identity crises (e.g. Arbetter, 1993) and variations such as "mistaken identity" (Forbes, August 29, 1994), "searching for a new identity" (Fitzgerald, 1993), a "split identity" (Murphy, 1996), which tend to reinforce a more psychological view of corporate identity. These conceptualisations however lack the psychological depth and sophistication generally observed in terms of the psychological concept of personal or individual identity. In practice corporate identity has not yet evolved to the point of incorporating the psychological fundamentals of the core or generic identity concept.

The reality that the identity of the organisation is more than the traditional concept of corporate identity (with its emphasis on visual cues) has been acknowledged. In this regard Olins (1990, p. 22) has stressed that the "visual promise" of corporate identity must be underpinned by an improvement in the communications or behaviour of the organisation. Furthermore, a new logo or brand will not secure a new identity if these organisational symbols do not adequately reflect internal organisational reality (Olins, 1996). Reflecting on the status of the corporate identity field, it must be concurred with Glover (1993) that too much emphasis has been placed on the world outside the organisation and not enough on the world inside it.

While corporate identity appears to be concerned more with the purposeful projection or portrayal of the organisation predominantly through planned and persuasive visual means, corporate image tends to be the result or effect of, among other, the efforts to project a desirable corporate identity. Descriptions of what a corporate image is, range from the relatively uncomplicated picture that a company's audiences have of it (Ind, 1990), to the more encompassing set of beliefs, experiences, feelings, knowledge, attitudes and perceptions stakeholders have of the organisation (Van Heerden \& Puth, 1995). Generally though, corporate image conceptualisations tend to vary around the common core of a perception of the company (Van Tonder, 1999). Shee's (1988) earlier observation that the majority of corporate image conceptualisations tend to view the concept as a manufactured rather than a true reflection of the organisation remains valid - particularly if the frequent references to the management of corporate image is considered (e.g. Schmitt, Simonson \& Marcus, 1995; Sutton \& Callaghan, 1987). The corporate image is essentially viewed as a marketing asset, a market-positioning device, and as part of the strategic agenda to be managed and designed for competitive advantage (Dowling, 1993; Stewart, 1991).

Of particular importance, is the claimed impact on the organisation's performance, of firstly, corporate identity, and secondly corporate image, which enjoys popular support. Success and successful organisations are frequently linked to corporate identity (Gorman, 1994; Olins, 1989; Simões \& Dibb, 2001; Smith, 1990), while authors such as Ackerman (1984) more directly argued that corporate identity clearly and consistently sheds light on business success and failure. Chajet (1988) more specifically stated that an inaccurate or inadequate corporate identity and perceptions of this identity (introducing the corporate image concept) will negatively impact on the company's sales and earnings, employee morale, ability to attract talented people and expansion capital, and general performance on Wall Street, while Melewar et al. (2001) cite numerous authors who have indicated that corporate identity programmes can reap financial rewards (attracting investment, raising capital, etc.). The potential payoff of corporate identity in terms of offering the organisation a distinct competitive advantage (Balmer \& Gray, 2000), or as a source of competitive differentiation (Melewar \& Navalekar, 2002) is widely acknowledged. Balmer and Dinnie (1999) moreover interpreted the results of a qualitative study (of limited scope) as offering support for corporate identity's effectiveness as an antidote to merger failure. While many of these arguments appear to have some face validity, few empirical studies have been produced in the area of corporate identity (Melewar, 2001). As empirical studies are rare, more research is clearly required before this relationship can be substantiated.

As with corporate identity, claims as to the impact of corporate image on organisational performance similarly abound (see for example Treadwell \& Harrison, 1994, who cite numerous studies in this regard). Despite this observation, substantive empirical research in this domain is also lacking (Shee, 1988; Stewart, 1991; Treadwell \& Harrison, 1994).

\section{Organisation identity}

In stark contrast to the proliferation of quasi-theoretical contributions in the field of corporate identity, the literature reveals a marked absence of contributions on the subject of organisation identity. Although each of the rather limited number of theoretical contributions made in respect of organisation identity practically represents a different perspective, four major streams or paradigms can be identified. For the purpose of categorisation and analysis these categories are referred to as the psychoanalytic, social identity, communication, and classical approaches to organisation identity.

The psychoanalytic approach, which is evidenced in the work of Diamond (1993) and Czander (1993), applies concepts from the domain of individual psychoanalytic theory to organisations. Diamond (1993) for example describes organisation identity as the unconscious foundation of organisation culture and suggests 
that organisation identity be seen as an interpretative framework, from which the organisation can be analysed and the motivation and behaviour of its members be understood. As a theoretical perspective, it relies intimately on the psychoanalytic tradition and concepts - in particular those relevant during childhood and later ego-development and for this reason the theory is difficult to apply to the organisation as unit of analysis.

The social identity approach, which is more concerned with the identity an employee or person derives from his/her membership of an organisation, is premised on the work of Tajfel (1974), and is represented more pertinently by the work of Ashforth and Mael (1989). Social identity theory argues that the individual seeks to obtain a positive social identity by virtue of membership to a group or groups (or organisations) that are held in high regard. It acknowledges the existence of either a group or an organisation with an identity sufficiently attractive or alluring for a potential member or stakeholder to seek belonging to it. It is only in this context that the notion of organisation identity - referring to the identity of the organisation as an entity - is introduced in the theory. It is argued that a distinctive organisation identity will attract potential employees, customers and shareholders to the organisation, and will enhance the support and loyalty of serving members (Ashforth \& Mael, 1989).

Both Diamond (1993) and Ashforth and Mael's (1989) articulation of organisation identity lean more towards the identity of the individual (as unit of analysis) and tend to understate the identity of the organisation-as-organisation (indeed may inadvertently diffuse the boundaries of the two identity concepts).

The communication approach to organisation identity (Hecht, 1993), essentially argues that organisation identity is a process of communication and self-expression, and messages about the self are exchanged during communication transactions. Identity is defined as a characteristic of the individual, stored as selfcognitions, feelings about self, and/or a spiritual sense of self or being. The character of the identity concept is clearly depicted through the basic assumptions of the theory, but the precise role and function of identity (its purpose) in terms of the overall functioning of the individual is less clear.

The fourth approach represents those researchers who focus on the identity of the organisation as an entity. The organisation identity concepts defined by these authors appear to incorporate one or more of the psychological parameters of the original identity concept as articulated by Erikson $(1959,1968)$. This school of thought is represented by the work of Albert and Whetten (1985), Dutton and Dukerich (1991), Dutton, Dukerich and Harquail (1994), and Van Tonder (1987) and can be referred to as the classical approach to organisation identity. Common to these authors, is the equation of organisation identity to the distinctive character of the organisation, which is evidenced in those features of the organisation that are considered core, distinctive, and enduring. In keeping with Erikson's $(1959,1968)$ views of individual identity, organisation identity is considered a life cycle bound phenomenon, which may become more salient during different development stages - particularly during change (for example transitions from one life cycle stage to another).

Apart from the above approaches which can be differentiated on the basis of the unit of focus and analysis (the organisation or the employee), the subject of organisation identity has also been approached from a strategy domain (Schoenberger, 1994), ethno-cultural perspectives, largely anchored in communication theory (Hecht, Collier \& Ribeau 1993), and from a marketing perspective (Christensen, 1995). Of the listed approaches, it is only the research by Albert and Whetten (1985), Dutton and Dukerich (1991), and more recently Van Tonder (1999) that attempted to extend the theory to some form of empirical exploration.
A brief comparison of the various contributions within the identified approaches indicates that the term organisation identity in most instances is a misnomer - frequently employed to indicate the identity of the individual employee. As such, it does not depict the organisation as unit of analysis, whose identity could more appropriately be referred to as organisation identity. Several of the theoretical perspectives consequently deal with the process of organisational identification - being the process through which individual employees obtain a positive identity by virtue of their involvement with the organisation.

A substantial degree of consistency is however observed in terms of the frequency with which the organisation's identity is equated to its character or personality (regularly used as synonyms) and, specifically, the distinctive/unique, central and enduring nature of the organisation. Secondly, while using different terminology such as frame of reference, schema, or cognitive gestalt, the theoretical contributions seem to suggest directly and often indirectly that organisation identity is an integration mechanism or framework. Organisation identity itself is largely unconscious or hidden and only becomes salient when the organisation engages change (whether by choice or otherwise), when it is challenged, or when it finds itself in transition between two life cycle stages. While Albert and Whetten (1985), and Van Tonder (1987) provide more evolved theoretical perspectives on organisation and group identity, adequately developed theories of organisation identity remain elusive. The problem is compounded by the alternate vantage points from which theorists approach the concept with or without regard for the psychological origins of the concept - a situation having its roots in the complexity and ambiguity of the psychological concept of identity and which prompted the restatement of the organisation identity concept by Van Tonder (1999).

Regardless of the perspective employed, it does appear as if most of the cited theorists would concur that identity has potentially serious ramifications and a significant impact which is often more indirect, pervasive and enduring than may be immediately apparent.

The respective contributors nominate a wide array of organisational attributes as important components for inclusion in the organisation's identity. Taken together, these include virtually all prominent features of the organisation and cover elements such as statements of ideology, mission, objectives, strategy, structure, organisational processes, shared values and beliefs, leadership, management philosophy, culture (frequently cited) and components of culture (such as rituals, ceremonies, stories, symbols), organisational boundaries, relationships (between employees, management and subordinates), logos, slogans, appearance of the corporate headquarters; organisational climate, the skills, abilities, attitudes and interests of the organisation; communication, feelings, social roles and social affiliations, and physical attributes of the organisation.

While culture, structure and to a lesser extent leadership and management, and ideology/mission are repeatedly mentioned, it appears that identity-defining attributes can be any attribute of an organisation, which attest to the uncertain understanding and hence conceptual parameters of the concept. To an extent, this also serves to confirm the absence of empirical research in the domain of organisation identity. Empirical observations will bring more clarity to this situation by differentiating between more and less prominent variables (features) of an organisation's identity.

Towards a theoretical framework for organisation identity From the various, though limited, theoretical contributions in the field, and drawing on Van Tonder's (1987) reconceptualisation of the identity construct, organisation identity was redefined as a dynamic cognitive gestalt or integrative schema of the organisation's features which reflect its uniqueness or distinctive, central/core and enduring character (Van Tonder, 1999). 
It is established largely at an unconscious level and provides the basis from which the organisation is consistently perceived as unique (one of a kind) and is clearly differentiated from other organisations in its environment (also referred to as the fact of identity or objective identity). The organisation's identity (or lack thereof) is experienced and expressed at a subjective level in the form of a sense of identity (referred to as subjective identity). This subjective identity of an organisation is an emotional manifestation of the more cognitive and objective identity (as stated above), and essentially describes the organisation's awareness of its identity (or lack thereof).

Van Tonder (1999) concluded that the purpose of organisation identity was to ensure that the organisation was perceived as a unique entity when compared to similar organisations. This it achieves through differentiating the organisation from its environment (through social comparison, introspection and self-categorisation processes), which in turn enhances focus and consequently facilitates adaptation, and the future survival of the organisation.

Moreover, organisation identity, which is established and maintained primarily at an unconscious level, is a life cycle linked phenomenon. It is sensitive to change during organisational transitions and in particular during periods when the organisation was more vulnerable and at risk (for example start-up conditions, rapid growth and decline stages in the organisation's life cycle).
Depending on the organisation's sensitivity to environmental conditions, and its capabilities for processing and internalising information from the environment, it could drift into a situation of identity diffusion or inadequate or inappropriate identity, which is referred to as an identity crisis. The latter if left unattended can seriously jeopardise the organisation's functioning in the short term, compromise intermediate adaptation to environmental change, and ultimately result in the organisation's demise.

With this conceptualisation as context it was argued that organisation identity as the distinctive character or central, distinctive and enduring features of the organisation, could be differentiated on theoretical grounds from corporate identity (essentially the visual portrayal of the organisation's character) and corporate image (the perceptions stakeholders have of the organisation). At the same time it provides substantive grounds for exploring the meaning and relevance of the organisation identity concept at an applied level.

A brief comparison of the alignment between identity concepts from different domains is presented in Table 2.

With the occasional exception, the preceding views in brief highlighted the general state of theory on the nature of organisation identity at the turn of the century - essentially fragmented, microscopic in focus, lacking in systemic

TABle 2

ALIGNMENT OF IDENTITY CONCEPTS FROM DIFFERENT DOMAINS (SOURCE: VAN TONDER, 1999)

\begin{tabular}{l} 
Personal Identity \\
\hline Objective Identity (the fact of identity) \\
which consists of a cognitive gestalt of \\
the individual, emphasising: \\
- Personal uniqueness \\
- Continuity over time and place \\
- Inner solidarity, unity, discreteness \\
and consistency of the person
\end{tabular}
and consistency of the person

\author{
A complex balance of individual and \\ general elements/characteristics, \\ which include: \\ - Biographical characteristics \\ - Historical features \\ - Roles \\ - Social positions and relationships \\ - Cultural inputs \\ - Group memberships \\ - Etc.
}

\section{Group Identity}

Objective (fact of) identity which consists of a cognitive gestalt of the group, emphasising

- The inner solidarity or psychological unity of the group (a sense of "us" or "we") and its boundaries

- The uniqueness of the group

- Its special character over time

- Group's control over own activities (autonomy)

The unvarying and permanent combination of group characteristics, including

- The group's specific social position within a network of inter-group relations, against a social historical context and timeframe.

- Strong environmental focus and relating to reference groups ("place markers")
Corporate Identity

An assembly of visual cues physical and behavioural - by which an audience can recognise and distinguish the company from others, and which can be used to represent or symbolise the company

A variety of features/components including at different stages:

- All the ways a company chooses to present itself

- Design, name, logo, relevant symbols

- Physical facilities

- Corporate mission, philosophy and culture

- Unique history, business mix, management style, communication policies, market and competitive distinction of the company, technological capabilities

- Personality, distinctive character, spirit, ethos

Emphasis: More contrived, constructed and projected as an idealised form rather than reflecting the true inner self of the organisation

Externally directed, communicative process with the environment (audiences), with the purpose of differentiating the organisation from other

Nature: Visual cues/features and a communicative process Claims to depict the distinctive character of the organisation Distinguished from Corporate image and reputation - both of which are specific types of perceptions held by audiences or stakeholders
Organisation Identity

An integrative framework or schem of the organisation's character or personality, which reflect the organisation's

- Uniqueness or distinctiveness when compared with other organisations

- Central character (the essence of the organisation)

- Enduring nature - degree of continuity or sameness over time

Organisational features/characteristics which emphasise the central, distinctive and enduring nature of the organisation, include:

- Ideology, mission, objectives, values and beliefs

- Strategy

- Structure

- Organisational processes

- Leadership, management philosophy, culture, climate

- Organisational boundaries

- Social role, affiliations

- Physical attributes (size, skills, etc.)

- Appearance (physical), logos, slogans, symbols, etc.

Emphasis on distinctive character or unique personality

Differentiate/distinguish the organisation from other organisations

Nature: Process

Differentiates between an objective identity (observable distinctiveness, core and central features, enduring character and experienced unity) and subjective identity: the awareness (sense) of identity. 
conceptualisation, frequently incoherent, and with a preponderance on the content of the definitional aspects of the phenomenon. It is however evident that since the initial surfacing of the identity concept in colloquial language, the meaning structure of the concept has evolved through several iterations of conceptual debate. The current perspectives on identity in an organisational setting, which appear to converge on the definition provided by Albert and Whetten (1985), represents a substantially altered and more sophisticated attempt to apply the identity concept in an organisational setting.

While progress has been made with the conceptual debate on identity and organisation identity, the converse is true for the empirical verification of the organisation identity phenomenon. Prior to Van Tonder (1999), empirical research on organisation identity was limited to a few attempts at exploring the concept by and large qualitative case study methodologies (Albert \& Whetten, 1985; Dutton \& Dukerich, 1991). This apparent reluctance by and large stems from the inadequacies of definitions of organisation identity and the absence of a supporting theoretical framework that could be subjected to systematic and rigorous empirical investigation. For the science of organisation identity to advance, attention should be shifted towards empirical research in order to solidify conceptual gains (in pursuit of a coherent theory of organisation identity). In this regard the study by Van Tonder (1999) is worthy of comment for it attempts to make progress at the level of the empirically observed phenomenon of organisation identity.

The study attempted to establish whether organisations possess distinctive identities and whether observed identities related to specific organisational attributes or features and the organisation's performance. An exploratory, ex post facto field study with qualitative and quantitative data gathering methods was employed and triangulation as methodology was pursued in the absence of a clear theory and empirical base. Both the independent variable (organisation identity) and the dependent variable (organisation performance) were operationally tested with several alternative definitions. In this regard organisation identity was alternatively conceptualised as the company's total answer to the question "who am I?"; distinctive character or personality; perceived uniqueness; and, that combination of organisational features which convey the unique, central or core, and enduring character of the organisation. Organisation performance in turn, was defined operationally as performance ratings provided by executives (covering a seven year period); published financial results for the 1997/1998 financial year; and overall rank order position of the company based on the frequency with which it has been cited in "top performing" and "worst performing" tables of the Top 100 Companies (annual Business Times survey) for a four year period. A cluster sampling strategy, drawing on companies resorting among the "Top 100" and worst performing companies on the Johannesburg Stock Exchange in the 1997 annual survey of Top 100 Companies (conducted by the Sunday Times Business Times) was employed. The participation of 10 listed companies in 7 industry sectors was secured. Data was obtained through structured interviews with 153 top and senior executives, who represented the participating companies.

In general it is reported that organisation identity was consistently observed (both as an objective phenomenon and as the subjective "sense of identity") regardless of how it was operationally defined, with organisations demonstrating distinct identities (in various stages of experienced adequacy or clarity) on a consistent basis. Results also revealed that organisation identity for this research population correlated consistently (and strongly) with specific sets of organisational features. More importantly, organisation identity consistently and in practically meaningful ways related to organisation performance. It was noted, in addition, that organisation identity ("distinctive character") correlated equally high with organisational focus and stage of organisational life cycle, and ultimately organisational performance. The author concludes that the empirical findings of the study were consistent with many of the theoretical assumptions regarding the nature of identity and it is suggested that processes of identity acquisition and the concept of identity crisis may be rewarding avenues for continued research. Van Tonder (1999) further asserted that the study, despite the non-probability (convenience) nature of the research sample, confirmed the relevance of organisation identity for organisational functioning, and indicated organisation identity's linkage (and sensitivity) to changes in the organisational life cycle. While the exploratory (and correlational) nature of the study precludes inferences about causality, the author argued that strong foundations for hypotheses in this direction have been established (Van Tonder, 1999).

While the conceptual advances in the domain of organisation identity entrenches the theoretical relevance of the concept, this study provided some credence to the empirical reality of organisation identity. It did so by demonstrating, firstly, that organisation identity is a phenomenon that differentiates organisations from one another, and secondly that it relates to the features, and more importantly, the performance, focus and development stage of the organisation. As such the study provides a foundation for a more intensified and focused research effort in terms of organisation identity - as a critical consideration in organisational functioning.

Turning to the current status of organisation identity research it is notable that contemporary debates (since 1999) convey a preponderance at a conceptual level with definitional aspects, which is reminiscent of the "paradigm proliferation" phenomenon observed in the field of organisation studies (Donaldson, 1995). The original definition of Albert and Whetten (1985) which equated organisation identity to that which is central, enduring, and distinctive about an organisation's character still occupies centre stage in current conceptual debates (e.g. Gioia, et al., 2000; Scott \& Lane, 2000). Those that participate in the argument about what organisation identity is, readily assimilate the "central" and "distinctive" nature of organisation identity. Under attack, is the definitional attribute "enduring" which is contested on the assumed connotation of rigidity or inflexibility - given a highly dynamic context (operating environment for organisations) and the increasing frequency and magnitude of organisational change. "Adaptive instability" (Gioia et al., 2000) is an illustration of the phrases that are coined to articulate and elevate the dynamic nature of organisation identity. Some scholars are of the view that the "enduring versus dynamic" argument is overstated (Scott \& Lane, 2000) and argue for a less dynamic/more stable quality ("stickiness" of the organisation's identity - Hogg \& Terry, 2000).

This debate on the malleability of identity "content", however, does not adequately recognise that identity content at any moment in time is a function and manifestation of the quality and effectiveness of the organisation's identity development and acquisition processes (Van Tonder, 1987). In effect the authors fail to adequately account for the purpose and role of identity in personality, and consequently the purpose and role of organisation identity in the "personality" of the organisation. The "how and why" of identity change, more appropriately, should concern itself with a more fundamental philosophy of organismic change linked to a theory of adaptation, development, and growth. Indeed, the process model of identity development and maintenance (Van Tonder, 1987) has proposed that identity is distilled from the reciprocal influence relationship existing between the environment and organisation. Identity content will accordingly be determined by the quality of the organisation's interaction with the environment, the quality of its data gathering processes (e.g. perception, observation) and the quality of its analytical processes (e.g. social comparison, self-categorisation and related 
introspective processes). In short, identity change will be a function of process - always within the context of prevailing environmental conditions (e.g. turbulence) - and will vary from organisation to organisation. Indeed it is against this context that Brown and Starkey's (2000) linking of organisation identity to learning and change offers a potentially more productive avenue for pursuing a holistic and coherent identity theory that will take account of the organisation's growth, and adaptation to changing environments.

Also prevalent from the more recent contributions, is the predominantly cognitive approach to viewing and articulating organisation identity and, despite a growing recognition of the value of identity in ascribing meaning to organisational life (e.g. Albert et al., 2000), and the natural reflection on emotional facets of functioning that identity offers (psychoanalytic theories of organisation identity), none of the current perspectives have as yet adequately recognised and distilled the subjective experience of identity (the "sense of identity") from the "objective" or cognitive constructionist identity of the organisation. The former is observed in the more psychologically inclined views of the identity concept (e.g. Erikson, 1959, 1963, Van Tonder, 1987) and has more recently been illustrated empirically in an organisational setting by Van Tonder (1999). Indeed, in organisational functioning, the sense of identity may well prove to be a more critical construct than the objective identity.

In general, contemporary contributions convey a commitment to the conceptual debate on organisation identity, but commitment to systematic empirical enquiry as vehicle for establishing a coherent theory of organisation identity - is less certain.

\section{Conclusion}

Reflecting on the progress made with the delineation and application of the identity concept, and in particular its spill over into the domain of organisational functioning - initially as corporate identity, but more recently as organisation identity - it would appear that the development of the identity concept has in a sense gone full circle. Current "calls" in the corporate identity field are proposing that the corporate identity concept incorporates a greater emphasis on the psychological and inherent character of the organisation, as opposed to the traditional emphasis on the organisation's appearance and visual attributes. In this sense contemporary views of corporate identity are converging with the classical perspectives of organisation identity, which in turn is firmly rooted in a psychological view of identity.

With regard to the development path of the organisation identity construct, it would appear that the critical, minimum level of conceptual mass needed for its theoretical differentiation from related concepts has been attained. The future relevance and significance of organisation identity will however be premised on empirical advances during the next stage of the construct's development.

Finally, the increasing awareness of identity and its prominence in the organisational context is a confirmation of the impact of rapid and turbulent change in the organisational environment, with its accompanying adaptation challenges to organisations. The question "who am I?" is brought into sharp focus when the organisation engages in adaptive change i.e. when greater alignment between organisation and environment is indicated. When organisations attempt to secure greater alignment with the environment for survival purposes - most notably in present times in the form of strategic repositioning, waves of mergers and acquisitions, downsizing or rightsizing, etc., the response to the identity question: "who am I?" emerges as a critical survival issue for the organisation. Identity and organisation identity as concepts, indeed, speak to the core of organisational adaptation, success, and longer-term survival.

\section{REFERENCES}

Abend, S.A. (1974). Problems of identity: Theoretical and clinical applications. Psychoanalytic Quarterly, 43, 606-637.

Ackerman, L.D. (1984). The psychology of corporation: How identity influences business. Journal of Business Strategy, 5, 56-65.

Albert, S., Ashforth, B.E., \& Dutton, J.E. (2000). Organizational identity and identification: Charting new waters and building new bridges. Academy of Management Review, 25, 13-25.

Albert, S., \& Whetten, D.A. (1985). Organizational identity. In L.L. Cummings \& B.M. Staw (Eds.), Research in organizational behavior, Vol. 7. Greenwich, CT.: JAI Press

Alessandri, S.W. (2001). Modelling corporate identity: a concept explication and theoretical explanation. Corporate Communications: An International Journal, 6 (4), 173-182.

Alvesson, M. (1990). Organization: From substance to image, Organization Studies, 11, 373-394.

Arbetter, L. (1993). Identity crisis. Security Management, 37 (4), 11.

Ashforth, B.E., \& Mael, F. (1989). Social identity theory and the organization. Academy of Management Review, 14, 20-39.

Balmer, J.M.T. (1995). Corporate branding and connoisseurship. Journal of General Management, 21 (1), 24-46.

Balmer, J.M.T., \& Dinnie, K. (1999). Corporate identity and corporate communications: the antidote to merger madness. Corporate Communications: An International Journal, 4 (4), 182-192.

Balmer, J.M.T., \& Gray, E.R. (2000). Corporate identity and communications: creating a competitive advantage. Industrial and Commercial Training, 32 (7), 256-261.

Balmer, J.M.T., \& Stotvig, S. (1997). Corporate identity and private banking: a review and case study. International Journal of Bank Marketing, 15 (5), 169-184.

Bourne, E., (1978). The state of research on ego identity: A review and appraisal, part I. Journal of Youth and Adolescence, 7, 223-251.

Brown, A.D., \& Starkey, K. (2000). Organizational identity and learning: A psychodynamic perspective. Academy of Management Review, 25 (1), 102-138.

Capowski, G.S. (1993) Designing a corporate identity. Management Review, 82 (6), 37-40.

Chajet, C. (1989). The making of a new corporate image. Journal of Business Strategy, 10 (3), 18-20.

Christensen, L.T. (1995). Buffering organizational identity in the marketing culture. Organization Studies, 16 (4), 651-672.

Christensen, L.T., \& Askegaard, S. (2001). Corporate identity and corporate image revisited: A semiotic perspective. European Journal of Marketing, 35 (3/4), 292-315.

Czander, W.M. (1993). The Psychodynamics of work and Organizations: Theory and application. New York: Guilford Press.

De Geus, A. (1997). The living company: Growth, learning and longevity in business. London: Nicholas Brearley Publishing.

Diamond, M.A. (1993). The unconscious life of organizations: Interpreting organizational identity. Westport, Connecticut: Quorum Books.

Donaldson, L. (1995). American anti-management theories of organization: A critique of paradigm proliferation. Cambridge: Cambridge University Press.

Dowling, G.R. (1993). Developing your company image into a corporate asset. Long Range Planning, 26 (2), 101-109.

Dutton, J.E., \& Dukerich, J.M. (1991). Keeping an eye on the mirror: Image and identity in organizational adaptation. Academy of Management Journal, 34, 517-554.

Dutton, J.E., Dukerich, J.M., \& Harquail, C.V. (1994). Organizational images and member identification. Administrative Science Quarterly, 39, 239-263.

Erikson, E.H. (1959). Identity and the life cycle. Psychological Issues, 1.

Erikson, E.H. (1968). Identity, youth, and crisis. New York: Norton.

Fitzgerald, M. (1993). Searching for renewed identity. Editor \& Publisher, September, 11-12.

Forbes. (1994). Mistaken identity, 154 (5), 284-285. 
Gioia, D.A., Schultz, M., \& Corley, K.G. (2000). Organizational identity, image, and adaptive instability. Academy of Management Review, 25, 63-87.

Glover, R.K. (1993). Identity building begins on the inside: External views reflection of a company's internal practices, habits. Business Marketing, August, 38.

Golnick, L.S. (1985). Creating a business identity, Banker's Monthly, 102 (11), 17.

Gorb, P. (1992). The psychology of corporate identity. European Management Journal, 10, 310-314.

Grossman, G. (1994). Carefully crafted identity can build brand equity. Public Relations Journal, 50 (8), 18-21.

Halloran, K.D. (1985). The impact of mergers and acquisitions on company identity. Mergers \& Acquisitions, 20, 64-65.

Hecht, M.L. (1993). 2002 - A research odyssey: Toward the development of a communication theory of identity. Communication Monographs, 60 (1), 76-82.

Hecht, M.L., Collier, M.J., \& Ribeau, S.A. (1993). African American communication: Ethnic identity and cultural interpretation. Newbury Park, CA: Sage.

Hogg, M.A., \& Terry, D.J. (2000). The dynamic, diverse, and variable faces of organizational identity. Academy of Management Review, 25 (1), 150-154.

Ind, N. (1992). The corporate image. London: Kogan Page.

Kiriakidou, O., \& Millward, L.J. (2000). Corporate identity: external reality or internal fit. Corporate Communications: An International Journal, 5 (1), 49-58.

Kohli, C. \& Hemnes, T.M. (1995). A corporation by any other name...? Business Horizons, 38 (6), 29-33.

Korten, D.C. (1995). When corporations rule the world. San Francisco: Berrett-Koehler Publishers.

Labich, K. (1994). Why companies fail. Fortune, 130 (10), 22-32.

Levinson, H. (1994). Why the behemoths fell: Psychological roots of corporate failure. American Psychologist, 49, 428-436.

Melewar, T.C. (2001). Measuring visual identity: a multiconstruct study. Corporate Communications: An International Journal, 6 (1), 36-41.

Melewar, T.C., \& Navalekar, A. (2002). Leveraging corporate identity in the digital age. Marketing Intelligence \& Planning, 20 (2), 96-103.

Melewar, T.C., Saunders, J., \& Balmer, J.M.T. (2001). Cause, effect and benefits of a standardised corporate visual identity system of UK companies operating in Malaysia. European Journal of Marketing, 35 (3/4), 414-427.

Murphy, C. (1996). Dunlop to sport a split identity. Marketing, June 27, 7.

O'Malley, M. (1992). Corporate identity and the built environment. Planning, 124, 58-59.

Offerman, L.R., \& Gowing, M.K. (1990). Organizations of the future: Changes and challenges. American Psychologist, 45, 95-108.

Olins, W. (1990). The corporate search for identity. Harvard Business Review, 68, 153-157.

Olins, W. (1996). The energy of identity. Marketing Focus, April, $18-20$.

Pitta, J. (1992). Identity crisis. Forbes, 149 (11), 82.
Robertson, D. (1999). Business leaders keenly focused on action. Sunday Times, Business Times, April 11, 1-1.

Schmitt, B.H. (1995). Language and visual imagery: Issues of corporate identity in East Asia. The Columbia Journal of World Business, 30 (4), 28-36.

Schmitt, B.H., \& Pan, Y. (1994). Managing corporate and brand identities in the Asia-Pacific region. California Management Review, 36 (4), 32-48.

Schmitt, B.H., Simonson, A., \& Marcus, J. (1995). Managing corporate image and identity. Long Range Planning, 28 (5), 82-92.

Schoenberger, E. (1994). Corporate strategy and corporate strategists: Power, identity, and knowledge of the firm. Environment and Planning A, 26, 435-451.

Scott, S.G., \& Lane, V.R. (2000). Fluid, fractured and distinctive? In search of a definition of organizational identity. Academy of Management Review, 25, 143-147.

Shee, P.S.B. (1988). The corporate image process. Unpublished master's research report, University of the Witwatersrand, Johannesburg.

Simões, C., \& Dibb, S. (2001). Rethinking the brand concept: new brand orientation. Corporate Communications: An International Journal, 6 (4), 217-224.

Smith, P.J. (1990). How to present your firm to the world. Journal of Business Strategy, 11, 32-36.

Stewart, K. (1991). Corporate identity: A strategic marketing issue. International Journal of Bank Marketing, 9 (1), 32-39.

Sutton, R., \& Callahan, A.L. (1987). The stigma of bankruptcy: Spoiled organizational image and its management. Academy of Management Review, 30, 405-436.

Tajfel, H. (1974). Social identity and intergroup behavior, Social Science Information, 13 (2), 65-93.

Treadwell, D.F., \& Harrison, T.M. (1994). Conceptualizing and assessing organizational image: Model images, commitment, and communication. Communication Monographs, 61 (1), 63-85.

Van Heerden, C.H. (1995). Corporate identity as an element of marketing strategy. Unpublished master's dissertation, University of Pretoria, Pretoria.

Van Heerden, C.H., \& Puth, G. (1995). Factors that determine the corporate image of South African institutions: An exploratory investigation. International Journal of Bank Marketing, 13 (3), 12-17.

Van Tonder, C.L. (1987). Kleingroepidentiteit. Unpublished master's thesis, Rand Afrikaans University, Johannesburg.

Van Tonder, C.L. (1999). Organisation identity: An exploratory study. Unpublished doctoral thesis, Rand Afrikaans University, Johannesburg.

Wathen, M. (1986). Logomotion: Corporate identity makes its move into the realm of strategic planning. Public Relations Journal, 42, 24.

Westin, C. (1983). Self-reference, consciousness and time. In A. Jacobson-Widding (Ed.), Identity: Personal and socio-cultural. Stockholm: Almqvist \& Wiksell.

Zinkhan, G.M. (1993). Advertising, design and corporate identity. Journal of Advertising, 22 (4), vii-ix. 